\title{
ÁGUAS NO DISTRITO FEDERAL: uma morte anunciada
}

\section{Karina Martins ${ }^{1}$ Kênia Rodrigues de Oliveira ${ }^{2}$}

\section{RESUMO}

A escassez de água é um fenômeno global, agravado pelo crescimento populacional, mudanças climáticas, desigualdade social, urbanização, industrialização, falta de manejo e usos sustentáveis dos recursos naturais. Problemas relacionados à escassez da água refletem diretamente na necessidade de aprimoramento de novas práticas de gerenciamento dos recursos hídricos sob os aspectos econômicos, sociais e ambientais. Analisa-se a água no Distrito Federal, os problemas de gestão e a escassez inevitável em não havendo uma Política Pública eficiente. A pesquisa caracteriza-se como qualitativa e descritiva. Concluiu ser necessário planejar e gerenciar os usos e definir prioridades, mantendo a água com qualidade para a presente e futuras gerações.

PALAVRAS-CHAVE: Água. Recursos hídricos, Gestão pública, Escassez, Política pública eficiente

\section{WATER IN THE FEDERAL DISTRICT: a death announced}

\begin{abstract}
Water scarcity is a global phenomenon, aggravated by population growth, climate change, social inequality, urbanization, industrialization, mismanagement and sustainable uses of natural resources. Problems related to water scarcity directly reflect the need for improvement of new water resources management practices from the economic, social and environmental aspects. Focusing on water in the Federal District, management problems and the inevitable scarcity in the absence of a efficient public policy. The research is characterized as qualitative and descriptive. It concluded that it is necessary to plan and manage uses and set priorities, maintaining quality water for present and future generations.
\end{abstract}

KEYWORDS: Water. Water resources, Public administration, Scarcity, Efficient public policy.

\section{Introdução}

\footnotetext{
${ }^{1}$ Doutoranda em direito pelo UniCEUB-DF. Mestre em Direitos Humanos, Cidadania e Violência com ênfase em Ciência Política pelo Centro Universitário Euro-Americano-DF. Especialista em Direito Agroambiental e Sustentabilidade pela Universidade Federal de Mato Grosso-UFMT/MT. Especialista em Direito e Processo Civil pela Universidade Cândido Mendes-UCAM/RJ. Advogada. Professora no Centro Universitário EuroAmericano - UniEURO-DF. (http://lattes.cnpq.br/3756055253190223).

2 Doutoranda em Direito pela UniCEUB; Mestre em Direito pela UniCEUB; Pós-graduação em Direito Penal pela UFG - Universidade Federal de Goiás e em Direito do Trabalho e Processual do Trabalho pelo Centro Universitário de Anápolis - Unievangelica; Graduação em Direito pelo Centro Universitário de AnápolisUnievangelica. Professora de Direito Civil e Processual Civil na Faculdade Evangélica de Goianésia-Go; Analista Judiciária do tribunal de justica de Goiás. (http://lattes.cnpq.br/3758956810515467)
} 
Até os mais céticos quanto à alteração do clima na Terra aceitam que mudanças climáticas tenham ocorrido de fato. Desde a frequência dos desastres naturais ao aumento da temperatura média do planeta. A controvérsia surge quando se discute a causa. Seria a própria natureza atravessando uma de suas fases, como as que no passado de séculos, provocaram o frio excessivo da idade do gelo? Explosões vulcânicas monumentais? Distúrbios na superfície do sol? Destruição maciça de espécies, como os dinossauros? Ou, a culpa é do ser humano em saga destruidora, consciente ou não, quando devora os recursos da Terra, polui o ar, solo e mar, na ânsia de produz mais, "buscar uma vida melhor”?

Vive-se uma época de grande crise civilizatória, em que a humanidade ainda não conseguiu, em seu conjunto, superar um modelo econômico que coloca o lucro acima da vida, gera profundas desigualdades e uma destruição sem precedentes do meio ambiente, colocando em risco a própria existência de vida na Terra. Os efeitos da ação humana no planeta em todas as suas vertentes, sendo a principal o aquecimento global, já são considerados pelos cientistas como uma mudança de era geológica: por conta de nossas ações desde a primeira Revolução Industrial, levamos o planeta Terra ao período denominado "Antropoceno", em que a instabilidade dos ecossistemas, a escassez e o desastre ambiental planetário tornam-se desafios chave cotidianos para a manutenção da vida (ÁVILA, 2018).

A água é um dos bens mais importantes deste século, nela se cumulam a riqueza e a vida. A mesma é provedora de poder e mantenedora da vida das espécies que habitam o planeta (ÁVILA, 2018). Por ser um recurso natural diretamente ligado à vida, a água possui utilidade para qualquer sociedade humana, sendo assim um recurso universal, independente do tempo e do espaço observados (PEREIRA, 2008).

E, por ser indispensável à manutenção da vida e dos seres humanos, o acesso à água doce constitui um direito fundamental, distinto do direito fundamental ao meio ambiente equilibrado, embora a ele diretamente relacionado, na medida em que pode ocorrer a hipótese de ter-se, em determinado local, o ambiente natural preservado, sem que as populações que lá se encontram tenham livre acesso aos recursos hídricos para suprir suas necessidades básicas (LEUZINGER, 2005).

Apesar de indispensável para a manutenção da vida e dos ecossistemas de modo geral, a pressão exercida pelas atividades humanas sobre os recursos hídricos vem gerando escassez, que tende a um agravamento nas próximas décadas, constituindo uma situação de estresse hídrico para grande parte da população do planeta (LEUZINGER, 2005). 
A necessidade de proteção dos recursos hídricos é medida de extrema urgência, não só no Distrito Federal como também em todo o mundo, uma vez que é imprescindível proteger os mananciais contra as diversas formas de poluição e de uso inadequado. Essa necessidade, no Brasil, se traduziu na criação de normas legais que pretendem planejar, regular e controlar a utilização dos recursos hídricos de acordo com padrões e critérios definidos mediante uma Política Nacional de Recursos Hídricos (PNRH), e implementados por meio de um Sistema Nacional de Gerenciamento de Recursos Hídricos (SNGRH) (SOAREZ, 2004).

Nesse sentir, formulou-se o seguinte problema de pesquisa: as legislações, gestões e políticas públicas adotadas pelo Governo no DF serão suficientes para garantir o acesso à água potável à população? Como hipótese, o trabalho assume que a estratégia adotada pelo Governo do DF diante a crise hídrica no período de 2017/2018 minimizou a escassez hídrica no Distrito Federal e entorno, todavia se faz necessário o estabelecimento de um sistema eficiente de gerenciamento e fiscalização desses recursos naturais, de forma a racionalizar o seu uso, evitando desperdícios.

Assim, o objetivo principal do artigo é o de analisar a água como recurso hídrico indispensável a manutenção humana, um bem juridicamente tutelado, perpassando pela sociedade de risco e a crise ecológica, focando na água no Distrito Federal, pontuando os problemas de gestão e a escassez inevitável em não havendo uma Política Pública eficiente.

\section{2. ÁGUA: um bem juridicamente tutelado}

A água é um dos mais importantes recursos para a existência da vida. Desempenha as mais variadas funções, como preservação da fauna e flora, abastecimento doméstico e industrial, irrigação, geração de energia, transporte e diluição de despejos (FIORILLO, 2013).

E, por ser indispensável à manutenção da vida e dos seres humanos, o acesso à água doce constitui um direito fundamental, distinto do direito fundamental ao meio ambiente equilibrado, embora a ele diretamente relacionado, na medida em que pode ocorrer a hipótese de ter-se, em determinado local, o ambiente natural preservado, sem que as populações que lá se encontram tenham livre acesso aos recursos hídricos para suprir suas necessidades básicas (LEUZINGER, 2005). 
Nessa lógica levou-se o legislador a lhe conferir especial atenção, inicialmente, com a edição do Código de Águas, ainda em 1934, voltado predominantemente para o seu aproveitamento hidrelétrico.

Ampla e variada é a legislação brasileira vigente sobre água. Nesse arcabouço incluise a Constituição Federal de 1988, as codificações e as leis esparsas. A Constituição colocou a água sob a proteção dos membros do pacto federativo ao garantir o meio ambiente como direito fundamental (artigo 225) (SILVA, 2015). Estabeleceu o legislador constituinte as águas superficiais ou subterrâneas como bens dos Estados (artigo 26, inciso I).

Na sequência, com a edição da Lei n. 9.433/97, instituiu-se a Política de recursos hídricos e criou normas específicas para sua gestão, que deve ser descentralizada e participativa, envolvendo o poder público, os usuários e a coletividade. Ademais, seguindo a orientação fixada pela Constituição Federal de 1988, declarou ser a água um bem de domínio público (artigo $1^{\circ}$, I) e reconheceu tratar-se de recurso limitado, dotado por isso de valor econômico (LEUZINGER, 2005).

A criação de uma Política Nacional de Recursos Hídricos e a criação de um Sistema Nacional de Gerenciamento de Recursos Hídricos, pela primeira vez na história do País, foi o objetivo, escopo principal, da Lei no 9.433/97. Concomitantemente, a Lei 9.984/2000, que criou a Agência Nacional de Águas - ANA - entidade federal de implementação da Política Nacional de Recursos Hídricos, integrantes do Sistema Nacional de Gerenciamento de Recursos Hídricos, estabeleceu regras para a sua atuação, sua estrutura administrativa e suas fontes de recursos.

\section{1. ÁGUA: sociedade de risco e crise ecológica}

O Planeta Terra tem sua superfície composta de $71 \%$ de água, distribuídas da seguinte forma, 97,5\% é composto por água salgada que se encontram nos mares, oceanos. Essas águas não são utilizadas para o consumo humano, visto que em sua composição apresenta alto teor de cloreto de sódio, variados sais minerais, que podem levar o ser humano à desidratação, e o uso na indústria e agricultura acarretam a destruição das máquinas e plantações, respectivamente (LIMA, s.d.). A água doce existente nos rios e nos lagos, corresponde a apenas $0,3 \%$ dos 2,5\% do total de água existente na Terra. Encontram-se 29,9\% desses 2,5\% no subsolo, nem sempre passível de exploração (LEUZINGER, 2017). 
O Brasil detém cerca de $12 \%$ da água doce superficial disponível no Planeta e $28 \%$ da disponibilidade nas Américas. Possui ainda, em parte de seu território, a maior reserva de água doce subterrânea, o Aquífero Guarani, com 1,2 milhão de quilômetros quadrados. Entretanto, a distribuição geográfica desses recursos - superficiais ou subterrâneos - é bastante irregular (SILVA, 2012).

Esse cenário de aparente abundância hídrica, no entanto, não tem sido suficiente para prover diversas regiões brasileiras com quantidades adequadas de água potável porque, além das interferências naturais e humanas no ciclo hidrológico, a distribuição desse recurso pelo território brasileiro também se dá de maneira heterogênea (LEUZINGER; SOUZA, 2019). A maior parte do suprimento doce disponível se concentra na Região Hidrográfica Amazônica (80\%) que detém o menor contingente populacional (5\%) e, consequentemente, a menor demanda (ANA, 2013). O restante do país vive a difícil missão de compatibilizar a baixa oferta de água (20\%) com alta demanda reclamada por $95 \%$ dos brasileiros, que é agravada ainda pelo fato de que algumas regiões são mais abastadas do que outras (LEUZINGER; SOUZA, 2019).

Reconhece-se a água como um bem de domínio público e um recurso natural renovável $^{3}$, todavia limitado, dotado de valor econômico, pois há um custo ambiental no seu uso que deverá ser mensurado pecuniariamente a fim de racionalizar o seu consumo, mas sem privar a população carente do mínimo necessário à sua dignidade. Sofre alterações de disponibilidade, qualidade e sustentabilidade no ecossistema, variando de acordo com modificações climáticas e formas de gestão (BARROS, 2008).

O processo de industrialização está, diretamente, associado ao processo de produção de riscos (BECK, 2010). A exposição da humanidade a riscos e inúmeras modalidades de contaminação, jamais observadas antes, constituem-se em ameaças aos habitantes e para o meio ambiente e são as principais consequências do desenvolvimento científico industrial. Esses riscos não afetam tão somente a sociedade atual, mas de forma mais agressiva às gerações futuras.

\footnotetext{
${ }^{3} \mathrm{O}$ ciclo da água envolve vários e complicados processos hidrológicos: evaporação, precipitação, interceptação, transpiração, infiltração, percolação, escoamento superficial, processo de escoamento sub-superficial. No entanto, a crescente urbanização das bacias hidrográficas promove alterações que modificam a dinâmica do ciclo da água (LIMA, 2008).
} 
O comportamento adotado pela humanidade frente aos riscos ambientais (BECK, 2010), deve ser modificado, sendo, portanto, necessário compreendê-los e aprofundar-se nos conceitos filosóficos de prudência e responsabilidade (ALENCASTRO, 2009).

Com o crescimento da atividade econômica e a produção industrial no último século houve um impacto violento sobre a biosfera. E o homem, como força geofísica preponderante (CRUTZEN, 2016) nos impactos terrestres, não para de investir em habitação, transporte, agricultura e indústria. Não obstante, às custas de matérias-primas de florestas, solos, mares e vias navegáveis (SOARES, 2004).

A teoria da Sociedade de Risco, desenvolvida frente ao caos ecológico que amedronta o mundo, apresenta-se o processo de transformação da sociedade moderna utilizando-se dos conceitos de perigo e risco (BECK, 2010), o faz demonstrando as particularidades da segunda modernidade vivenciada pela atual sociedade de risco (MORAES, 2012).

A humanidade, no século XX, vivenciou inúmeras catástrofes históricas, as quais contribuem para os problemas da sociedade atual (BECK, 2010). Se antes, na sociedade industrial, produzia-se riquezas, hoje, na sociedade de risco, as riquezas produzidas são acompanhadas de riscos.

Num comparativo entre sociedade industrial e a sociedade de risco demonstra-se que aquela mantinha-se coesa pela solidariedade de carência. $\mathrm{Na}$ sociedade de risco a solidariedade surge pelo medo, convertendo-se em força política. Assim, verificou que todos os seres humanos possuem um lugar no tecido social, longe da miséria e da escassez, mas surge um novo elemento, simbolizado pelo medo que surge quando se percebe os riscos. Enquanto a sociedade industrial relaciona-se com o ideal de igualdade, a sociedade de risco apresenta como seu ideal a segurança, denominado de solidariedade do medo (BECK, 2010).

A sociedade contemporânea vive uma crise de paradigma, a crise do sonho maior que deu sentido ao mundo moderno: o desenvolvimento ilimitado, a vontade de poder como dominação (BOFF, 2009). Esta racionalidade moderna é que provocou a contaminação das águas, o envenenamento dos solos, a urbanização maciça de regiões ecologicamente frágeis, as chuvas ácidas, o depósito de detritos nocivos, a desertificação, a erosão, o desmatamento, a salinização dos solos, as inundações, as emissões de gás carbono, que intensificam o efeito e a decomposição gradual da camada de ozônio. 
Segundo a ONU, aproximadamente $20 \%$ da população mundial não tem acesso a água potável e cerca de $40 \%$ não dispõe de água suficiente para uma estrutura adequada de saneamento básico e higiene. Em 20 anos, a quantidade média de água disponível para cada indivíduo será reduzida a um terço da atual. Em 2050, a depender das taxas de crescimento populacional e das iniciativas políticas tomadas para minorar a crise, a escassez de água afetará quase 3 bilhões de pessoas. Nos países em desenvolvimento, a demanda por água deverá crescer significativamente, em virtude do aumento populacional aliado às expansões industrial e agrícola ${ }^{4}$. Os países desenvolvidos, entretanto, continuarão a apresentar maiores índices de consumo per capita (SILVA, 2012).

O desenvolvimento sustentável é, evidentemente, incompatível com o jogo sem restrições das forças do mercado (SANCHS, 2002). O paradigma do modelo de modernidade colocou em risco o bem mais precioso e fundamental existente: a perpetuação da vida e, paradoxalmente, a própria existência humana na Terra (BOFF, 2009).

As condições do meio natural e da influência da atividade humana sobre o meio ambiente determinam a formação de uma sociedade sustentável na gestão dos recursos hídricos.

\subsection{DESENVOLVIMENTO SUSTENTÁVEL: a necessidade de uma atenção diferenciada à gestão dos recursos hídricos}

No aspecto ambiental, o desenvolvimento refere-se à necessidade de gerenciar recursos naturais de um modo prudente, devido ao fato de que o bem-estar humano depende intimamente dos serviços ambientas (MARVILA, s.d). Ignorar os limites da segurança ecológica implica elevar o risco de debilitar perspectivas de desenvolvimento à longo prazo (ARAUJO, 2008).

A sustentabilidade, no sentido de capacidade de não causar danos às pessoas, comunidades ou ao meio ambiente, nem tampouco de esgotar recursos naturais, dando respaldo ao equilíbrio social e ecológico a longo prazo (CONAB, 2018), torna-se mais importante para a cadeia produtiva e à sociedade. Existe maior conscientização de que um equilíbrio saudável entre prosperidade e bem-estar é essencial para a construção de uma

\footnotetext{
${ }^{4}$ A agricultura responde hoje por $70 \%$ do consumo mundial de água. A expansão das fronteiras agrícolas tem, portanto, significativo impacto sobre a disponibilidade hídrica, tornando-se imprescindível o desenvolvimento e a aplicação de novas tecnologias que reduzam o consumo de água destinada à irrigação.
} 
sociedade sustentável e que as melhores soluções são criadas por meio da cooperação, da atuação do Estado conjuntamente com demais atores, diretos e indiretos, da cadeia produtiva.

O desenvolvimento sustentável é um desafio planetário. Ele requer estratégias complementares (SANCHS, 2002), não só entre o Norte e o Sul. Parte-se do pressuposto que o Estado pode obter melhores resultados de sua atuação com o estabelecimento de parceria entre o setor público, o setor privado e o terceiro setor, aquelas devem surgir de uma construção coletiva e participativa, envolvendo diferentes facetas do Estado, representantes de organizações não governamentais, empresas privadas e entidades representativas de setores da economia do Estado.

A água possui um valor inestimável. Além de ser um insumo indispensável à produção, é um recurso estratégico para o desenvolvimento econômico, a água constitui fator determinante na manutenção dos ciclos biológicos, geológicos e químicos que garantem equilíbrio aos ecossistemas (CAPOBIANO, 1999). É ainda um bem cultural e social indispensável à sobrevivência e à qualidade de vida da população (GRAF, 2000).

A escassez de água é um fenômeno mundial, agravado pelo crescimento populacional, mudanças climáticas, desigualdade social, urbanização, industrialização, falta de manejo e usos sustentáveis dos recursos naturais (ARAUJO, 2018).

Diante da realidade hídrica mundial passamos a enfrentar diversas crises, cada vez mais recorrentes e espalhadas pelo globo. No Brasil os problemas relacionados à escassez de água agravam-se ao longo dos últimos anos, refletindo diretamente na necessidade de se aprimorar novas práticas de gerenciamento dos recursos hídricos sob os aspectos econômicos, sociais e ambientais.

A poluição das águas é um mau grave e silencioso. O estarrecimento social e a atuação do Estado, no entanto, geralmente acontecem de forma mais enfática quando há algum fenômeno negativo visível, como a morte em massa de peixes, a produção de espuma (SUPERINTERESSANTE, 2016) ou a contaminação de pessoas e animais.

Raras, porém, são as iniciativas que vinculam enfaticamente o desmatamento, a ocupação desordenada do solo e a poluição, à manutenção da qualidade e da quantidade da água. O Estado, a quem compete coibir e informar, pouco ou nada faz para estabelecer esse link, no que tange apenas a pequenos exemplos do impacto causado pela atuação humana no meio ambiente (LEUZINGER; SOUZA, 2019). 


\section{3. ÁGUA NO DISTRITO FEDERAL: da abundância à escassez}

A região é berço de três das principais bacias hidrográficas do Brasil. A Bacia do São Francisco é constituída pela Bacia do Rio Preto, cujas nascentes principais se encontram na cidade de Formosa. Seus afluentes mais expressivos são: Ribeirão Santa Rita, Ribeirão Jacaré, Ribeirão Extrema, Rio Jardim e Ribeirão São Bernardo.

A Bacia do Tocantins/Araguaia é formada pelas bacias do rio Maranhão e Paraná. A principal nascente do Maranhão encontra-se em Planaltina, dentro da Reserva de Águas Emendadas, e recebe como afluentes Ribeirão Palmeiras, Ribeirão Sonhim, Ribeirão da Contagem, Ribeirão das Pedreiras, Ribeirão Cafuringa, Rio das Palmas, Ribeirão Dois Irmãos e Rio do Sal. O rio Paraná tem como seu principal formador o rio Itiquira, que nasce em Formosa.

Por último, a Bacia do Paraná é formada pelas bacias hidrográficas do Lago Paraná, Rio São Bartolomeu, Rio Descoberto, Rio São Marcos e Rio Corumbá. Dentro da reserva de Águas Emendadas se encontra o Ribeirão Mestre d'Armas, formador do Bartolomeu (ELEUTÉRIO, 2017).

Isto se explica pela caracterização do Cerrado, que é o segundo maior bioma do país, com reservatórios subterrâneos imensos que abastecem rios e nascentes e alimenta três dos maiores aquíferos do mundo, a Bacia do Paraná, Bacia do Tocantins/Araguaia e Bacia do São Francisco.

Contudo, depois da Mata Atlântica, o Cerrado é o bioma brasileiro que mais sofreu alterações com a ocupação humana, com o uso desordenado do solo e o avanço do agronegócio. Como resultado da ocupação desordenada da região central, grandes áreas de Cerrado foram desmatadas, sendo o Bioma Cerrado atualmente considerado como um dos 25 ecossistemas do planeta, com alta biodiversidade, que está ameaçado.

As estimativas de áreas degradadas ou em uso no Cerrado são de 50\% a 80\% do Bioma, sejam elas áreas agrícolas, pastagens ou áreas degradadas sem uso. Mesmo com esse cenário, pouco menos de 4,5\% de área do Cerrado está protegido em Unidades de Conservação, o que justifica o título dado de segundo Bioma mais ameaçado do Brasil.

Por esta razão, pela qual o Cerrado abriga importantes áreas de mananciais, Áreas de Proteção de Mananciais (APM) foram instituídas pelo art. 30 da Lei Complementar $n^{\circ}$ 17, de 
28 de janeiro de 1997, regulamentadas pelo Decreto Distrital $n^{\circ} 18.585$, de 9 de setembro de 1997.

A APM é aquela destinada à recuperação ambiental e à promoção do uso sustentável nas bacias hidrográficas a montante dos pontos de captação de água destinada ao abastecimento público, sem prejuízo das atividades e ações inerentes à competência da concessionária de serviço público autorizada a captar e distribuir água de boa qualidade e em quantidade suficiente para o atendimento da população.

Segundo Mapa Ambiental definido pelo Instituto Ambiental de Brasília -IBRAM, o DF possui as APM's: do Alagado, do Bananal, do Barrocão (Brazlândia), do Brejinho, do Cabeça de Veado, do Cachoeirinha, do Capão da Onça, do ribeirão do Gama (Catetinho), do Contagem, do Corguinho, do Crispim, do Currais, do Engenho das Lages, do Fumal, do Mestre d'Armas, do Olho d'Água, do Paranoazinho, do Pedras, do Pipiripau, do Ponte de Terra, do Quinze, do Santa Maria, do São Bartolomeu (partes Norte e Sul), do Taquari e do Torto (IBRAM, 2014).

A gestão, o monitoramento e a fiscalização das APMs competem ao órgão gestor do desenvolvimento territorial e urbano e ao órgão gestor da política ambiental do Distrito Federal, devendo cooperar com os órgãos gestores os órgãos responsáveis pela política rural do Distrito Federal e o órgão gestor da fiscalização, bem como a Agência Reguladora de Águas e Saneamento do Distrito Federal - ADASA/DF e a concessionária de serviço público autorizada e responsável pela captação. A gestão das APMs deverá estar integrada com o processo de gestão de bacias hidrográfica (IBRAM, 2014).

\subsection{PROBLEMAS DE GESTÃO: alicerce para crise hídrica no DF}

O Brasil é o detentor da maior reserva de água doce do mundo, todavia o país sofre com a crise hídrica sem apresentar estratégias precisas para enfrentar o problema e garantir o abastecimento de forma sustentável (BARROS, 2008).

Destaca-se que 57\% do território do Distrito Federal compõem-se de terras altas, servindo como dispersoras das drenagens que fluem para as três mais importes bacias fluviais do Brasil: Prata, Araguaia-Tocantins e São Francisco (SANTILLI, 2001). O cerrado é conhecido como o "berço das águas" e, no Distrito Federal, a Estação Ecológica de Águas Emendadas abriga o fenômeno único da união das bacias hidrográficas do Tocantins/Araguaia 
e Platina, em uma vereda de seis quilômetros de extensão. As águas emendadas funcionam como um corredor ecológico, interligando a fauna e a flora das duas bacias (JOACHIM KRELL, 2002).

Não obstante as belezas naturais e o complexo hídrico brasiliense, o Distrito Federal, corre grande risco de escassez, visto o crescimento populacional desordenado e irregular do território, desmatamento, falta de conscientização popular quanto à conservação da vegetação nativa, esgotos, fossas sépticas; parcelamento do solo urbano e rural; atividades extrativas, como retirada de terra, areia, pedras, etc.; deposição de lixo e entulho; queimadas; escoamento inadequado de águas fluviais, provocando erosão; caça e pesca ilegais; invasões; práticas agrícolas inadequadas; construção de estradas sem os critério técnicos adequados e limitações ao adensamento da bacia (JOACHIM KRELL, 2002).

Brasília, a exemplo dos municípios brasileiros, tem uma gestão das águas urbanas caracterizada por uma visão pouco integrada, com adoção de soluções tradicionais e ultrapassadas de drenagem urbana, não está adequadamente sensibilizada para enfrentar as mudanças climáticas (ANDRADE, 2019).

Com um adensamento populacional de cerca de 60 mil pessoas por ano, o Distrito Federal é uma zona com potencial para escassez hídrica. Afirma-se que a taxa de crescimento na população do DF é duas vezes maior que a média nacional (AUGUSTO FERNANDES, 2019). Com isso os recursos hídricos na unidade da Federação correm o risco de ficarem cada vez menos abundantes para abastecer os brasilienses.

A população de Brasília cresce 2,25\% a cada ano. Em contrapartida, a quantidade de água no DF ou diminui ou mantém o mesmo nível. Como consequência, cada cidadão do DF tem menos de mil metros cúbicos à disposição para utilizar o ano inteiro (AUGUSTO FERNANDE, 2019). Este é um número baixíssimo.

Cabe salientar que além da utilização dos recursos hídricos para o abastecimento humano, a água do DF é largamente utilizada pela agricultura. São pelo menos 16 mil hectares irrigados. Em período de seca, quando os agricultores mais precisam desse recurso, a captação de água pelo setor é muito maior do que para abastecimento humano.

Além dos efeitos das mudanças climáticas, a cidade planejada para o automóvel vem sofrendo com o desmatamento do Cerrado, a degradação socioambiental, assoreamento de mananciais e nascentes, excessiva impermeabilização do solo, com construções de novas vias, viadutos e possibilidades de novas expansões urbanas e em áreas sensíveis, como as 
planejadas para a Serrinha do Paranoá, região produtora de água na Bacia do Paranoá (ANDRADE, 2019).

Por falta de uma política habitacional efetiva para a classe de renda mais baixa, alto custo da terra que impossibilita o acesso à moradia em regiões centrais, as ocupações urbanas periféricas incidem sobre áreas rurais ou de preservação ambiental, denominadas "desordenadas" pelo governo. Com ligações "clandestinas", não recebem os serviços de saneamento, sem a regularização, gerando impactos na saúde dessas populações e dos ecossistemas (ANDRADE, 2019).

Há, no entanto, uma certa urgência na adoção dessas medidas porque a situação está tão caótica que se não houver uma mudança profunda de comportamento, tanto na esfera individual como coletiva, no que tange à conservação dos recursos naturais, dentre os quais se incluem os hídricos, a preocupação não será mais com o bem-estar econômico e social, mas com a manutenção de padrões mínimos de sobrevivência (VIEGAS , 2007).

Frisa-se, portanto, a necessidade de toda a população manter a consciência de não desperdiçar água, sobretudo após o racionamento entre janeiro de 2017 e junho de 2018, diante da crise hídrica no Distrito Federal e entorno.

\subsection{ESCASSEZ: a busca de uma Política Pública eficiente}

A crise de água não é consequência apenas de fatores climáticos e geográficos, mas principalmente do uso irracional dos recursos hídricos. Entre as causas do problema figuram: o fato de a água não ser tratada como um bem estratégico no País, a falta de integração entre a Política Nacional de Recursos Hídricos (PNRH) e as demais políticas públicas, os graves problemas na área de saneamento básico e a forma como a água doce é compreendida, visto que muitos a consideram um recurso infinito (SILVA, 2012).

Para preservar os corpos hídricos e garantir o acesso a eles, o Brasil terá de promover uma gestão eficiente, que busque a equalização inter-regional e intertemporal da água. Para a definição dos marcos regulatórios principais e da capacidade de suporte de cada bacia, é fundamental o conhecimento das necessidades dos diversos usuários e da capacidade de oferta e de renovação das fontes naturais (FREITAS, 1999).

O comprometimento da qualidade da água pela contaminação por esgotos domésticos, muitas vezes lançados no ambiente sem tratamento prévio, implica, entre outras 
consequências, o aumento da incidência de doenças de veiculação hídrica, como cólera, diarreia, amebíase e esquistossomose. Essa preocupação assume proporções mais graves em países ou regiões onde é maior a pobreza. Nos países em desenvolvimento, $90 \%$ das doenças infecciosas são transmitidas pela água (FREITAS, 1999).

A solução desses problemas passa pela adoção de políticas públicas eficazes. Devido à escassez de recursos financeiros, o tratamento de água e de esgotos é, por vezes, relegado a segundo plano. No Brasil, o maior percentual de residências sem instalações sanitárias ocorre nas regiões Norte e Nordeste, que concentram a população mais carente do País. O índice de mortalidade infantil guarda relação inversa com a porcentagem de domicílios atendidos pelos serviços de distribuição de água e coleta de esgotos. As consequências das más condições de saneamento são agravadas pela falta de informação, mais comum entre a população de baixa renda.

A racionalização do uso dos recursos hídricos passa pela redução do consumo, a reutilização e a reciclagem. A redução do consumo diz respeito à simples economia de água, por meio da eliminação de vazamentos e da diminuição do gasto em atividades domiciliares, industriais e agrícolas, entre outras. A reutilização pode ser definida como o uso de água já utilizada para determinada função, mesmo que sua qualidade tenha sido reduzida durante esse uso inicial; o reaproveitamento é feito antes que essa água atinja a rede de esgoto. A reciclagem consiste no reaproveitamento da água que já passou pela rede de esgoto e por uma estação de tratamento.

As políticas de planejamento, uso do solo, preservação ambiental, habitação, transporte, energia, resíduos são integrados à gestão, proteção e conservação do ciclo urbano da água. A paisagem é desenhada para gerenciar fluxos e reciclar a água com técnicas de infraestrutura ecológica: biovaletas, jardins de chuva, bacias de infiltração, sistemas de biorretenção ou bioinfiltração, alagados construídos, bacias de detenção ou retenção e telhados verdes. Todos os locais da cidade, incluindo edifícios, estradas, caminhos e espaços abertos são utilizados para promover a gestão total do ciclo urbano da água (ANDRADE, 2019).

Vale ressaltar que apesar de os recursos hídricos do Distrito Federal ter um dos menores índices de disponibilidade do país, a região tem uma potencialidade suficiente para garantir o abastecimento da sua população. Não obstante se faz necessário o estabelecimento 
de um sistema eficiente de gerenciamento e fiscalização desses recursos naturais, de forma a racionalizar o seu uso, evitando desperdícios.

Noutro sentir é fundamental a participação da comunidade no sentido de criar alternativas para recuperação e conservação dos mananciais. A sensibilização e uma política eficiente de educação ambiental em todos os segmentos da sociedade são formas apropriadas para tal política.

\section{Considerações finais}

O estudo sobre as crises hídricas recentes no mundo indica que o crescimento populacional, padrão cultural de consumo, mudança climática, uso e ocupação do solo, alterações na qualidade da água e ausência de gestão eficaz de recursos hídricos, associada às estruturas físicas deterioradas estão entre as principais causas desses episódios. As medidas utilizadas para solucionar essas situações são, em grande parte, emergenciais, reativas e com resultados no curto prazo.

As crises hídricas vividas ou vivenciadas pelos estados brasileiros, no entanto, têm em comum a forma pela qual a sociedade e o Poder Público têm se posicionado frente a esses problemas, que pode ser traduzida em ações tardias e insuficientes.

Nesse contexto, percebe-se que a implementação de ferramentas da gestão integrada de recursos hídricos é essencial para a resolução de situações de escassez de água e conflitos de uso dos recursos hídricos, por meio de implementação de medidas de adaptação, com o objetivo de manutenção da segurança hídrica dos sistemas no longo prazo. Os processos de tomada de decisão devem ser realizados de forma participativa, incluindo os setores usuários.

A severidade da situação exige a adoção de medidas rápidas e eficientes. O clamor por celeridade e eficiência, porém, não está relacionado a soluções imediatistas, mas à agilidade na implementação de um plano de ação que considere todas as variáveis, que atue em todas as frentes, com a participação do Estado e da sociedade, congregando ações que despertem, ao mesmo tempo, a consciência sobre o uso racional e a preservação dos recursos ambientais e hídricos.

De todas as crises ambientais, a hídrica é uma das mais sensíveis porque a sua indisponibilidade interfere, por exemplo, na saúde, no consumo humano, na economia e na produção de alimentos, dependendo para o seu equacionamento do desenvolvimento de ações 
simultâneas que incluem o afastamento da cultura do desperdício, as ações de reflorestamento, a adoção de construções sustentáveis, a implementação de novos sistemas de reutilização de água, a expansão das medidas de saneamento básico, entre outros.

O prenúncio de um cenário hídrico, no qual, a indisponibilidade de água seja recorrente, pode provocar uma verdadeira convulsão social cuja ocorrência ou não está relacionada à modificação do comportamento irresponsável até então adotado pelo homem. Todavia, a adoção de uma nova conduta que diminua ou elimine o impacto humano sobre o meio ambiente não ocorrerá num passe de mágica, já que a educação é um processo de aprendizado constante.

Os erros atuais e do passado demonstram que mesmo as sociedades mais intelectualizadas podem fracassar por ignorar ou subestimar a gravidade de seus problemas ambientais, o que confere à educação ambiental papel ainda mais relevante na formação de uma consciência hídrica.

Destaca-se, nesse ponto, a necessidade de viabilidade ambiental, técnica e econômica para que essas ações sejam implementadas pelos usuários de água. Além disso, são necessárias campanhas educacionais para a conscientização sobre o uso da água e capacitação técnica dos usuários para a adoção dessas medidas.

O desenvolvimento de políticas públicas, projetos de financiamento e incentivos fiscais também influenciam positivamente para que a implementação dessas medidas não faça parte apenas de etapas de planejamento, mas que sejam executadas na prática.

\section{Bibliografia}

ALENCASTRO, Mario Sergio. Hans Jonas e a proposta de uma ética para a civilização tecnológica. Desenvolvimento e meio ambiente, v. 19, 2009.

ANA. Relatório de Conjuntura dos Recursos Hídricos traz balanço da situação e da gestão das águas no Brasil. em:<http://www2.ana.gov.br/Paginas/imprensa/noticia.aspx?id_noticia=12365>. Acesso em: 8 fev. 2019.

ANDRADE, L. M. SO. DE. Brasília sensível à água, sem inundações, sem escassez hídrica e com inclusão social. UNB Notícias, 2019.

ARAÚJO, G. F. Estratégias de Sustentabilidade: aspectos científicos, sociais e legais: contexto global: visão comparativa. 1. ed. São Paulo: Editora Letras Jurídicas, 2008. 
ARAUJO, R. L. DE. Uma Análise da Crise Hídrica e da Gestão dos Recursos Hídricos no Distrito Federal, 2018.

AUGUSTO FERNANDES. DF sempre foi zona com potencial à escassez hídrica. Correio Braziliense, 2019.

ÁVILA, T. A crise da água no DF e Entorno. Fórum Alternativo Mundial da Água. Anais. 2018

BARROS, Fernanda Gene Nunes; AMIN, Mário M. Água: um bem econômico de valor para o Brasil e o mundo. Revista Brasileira de Gestão e Desenvolvimento Regional, v. 4, n. $1,2008$.

BECK, U. Sociedade de risco. São Paulo: Editora 34, 2010.

BOFF, L. A opção terra: a solução para a terra não cai do céu. Rio de Janeiro: Record, 2009.

BRASIL. Companhia Nacional de Abastecimento - CONAB. Conjuntura Mensal de Soja Análise Mensal, maio 2018. Disponível em: <https://www.conab.gov.br/info-agro/analisesdo-mercado-agropecuario-e-extrativista/analises-do-mercado/historico-mensal-de-

soja/item/download/19698_c63ed7bf8be469621eaca73f159b2ad0>. Acesso em: 07 fev. 2019. CAPOBIANCO, João Paulo Ribeiro. Fonte de água pura. Resenha do livro Águas doces do Brasil: capital ecológico, uso e conservação, Escrituras, coordenação de Aldo Rebouças, Benedito Braga e José Galizia Tundisi. Parabólicas, n. 55, nov./dez. 1999. (http://socioambiental.org/parabolicas/ index.html).

CRUTZEN, Paul J. Geology of mankind. In: Paul J. Crutzen: A Pioneer on Atmospheric Chemistry and Climate Change in the Anthropocene. Springer, Cham, 2016. p. 211-215.

ELEUTÉRIO, Robson. Na rota das nascentes: a história da região do Distrito Federal. Brasília, 2013. Disponível em http://cerratense.com.br/patrimonionarota.html, acesso em 05 fev 2019.

FIORILlO, Celso Antônio Pacheco; FERREIRA, Renata Marques. Curso de direito da energia. Editora Saraiva, 2013.

FREITAS, Marco Aurélio Vasconcelos de \& SANTOS, Afonso Henriques Moreira. Importância da Água e da Informação Hidrológica. In: O Estado das Águas no Brasil. Brasília: ANEEL e ANA, 1999.

GRAF, Ana Claudia Bueno. Água, bem mais precioso do milênio: o papel dos Estados. Revista CEJ, v. 12, p. 30-39, 2000.

IBRAM - INSTITUTO BRASília AMBIEnTAL. Mapa Ambiental do DF. 2014. Disponível

em

<http://www.ibram.df.gov.br/pdfs/institucional/Mapa\%20Ambiental\%202014.pdf> Acesso em 25 fev. 2019.

JOACHIM KRELL, Andreas et al. Problemas e desafios do gerenciamento dos recursos hídricos no Distrito Federal: a aplicabilidade da Lei N. 9.433/97. 2002. Dissertação de Mestrado. Universidade Federal de Pernambuco.

LEUZINGER, M. D.; BINDER, C. A. A ATUAÇÃO DOS ADVOGADOS PÚBLICOS NA DEFESA DO MEIO AMBIENTE: biodiversidade, clima e água. Direito do Estado em Debate, v. 8, p. 211-244, 2017.

LEUZINGER, Márcia. Recursos Hídricos. In: RIOS, Aurélio Virgílio Veiga; IRIGARAY, Carlos Teodoro Hugueney. O Direito e o desenvolvimento sustentável. São Paulo: Peirópolis; Brasília: IEB, 2005.

LIMA, E. T. D. DE; ARGENTON, J.; ADAME, A. O reuso da água como forma de sustentabilidade para diminuição da escassez. [s.d.]. Disponível em < http://www.site.ajes.edu.br/congre/arquivos/20161204220144.pdf> Acesso em 25 fev. 2019. 
MARVILA, Luciano de Almeida. ESCASSEZ DE ÁGUA. Rio de janeiro: s.d.

MORAES, K. G.; CAVALCANTE FERREIRA, M. E. P.; RDRIGUES FERREIRA, V. A sociedade contemporânea: Uma sociedade de risco. In: OUTROS, A. A. E. Agrotóxicos: a nossa saúde e o meio ambiente em questão - aspectos técnicos, jurídicos e éticos. [S.1.]: Direito e Saúde, v. 3, 2012. p. 382.

PEREIRA, A. O. K.; CALGARO, C. A água: os reflexos da modernidade. Revista de Doutrina da $4^{\text {a }}$ Região, v. 23, 2008.

SANCHS, Ignacy. Caminhos para o Desenvolvimento Sustentável. Tradução José Lins Albuquerque Filho. Rio de Janeiro: Garamond, 2002.

SANTILLI, Juliana Ferraz da Rocha. A política nacional de recursos hídricos: Lei $\mathbf{n}^{\mathbf{o}}$ 9.433/97 e sua implementação no Distrito Federal. In: Revista da Fundação Escola Superior do Ministério Público do Distrito Federal e Territórios, Brasília, v. 9, n. 17, jan./jun. 2001, p. 174.

JOACHIM KRELL, Andreas et al. Problemas e desafios do gerenciamento dos recursos hídricos no Distrito Federal: a aplicabilidade da Lei N. 9.433/97. 2002. Dissertação de Mestrado. Universidade Federal de Pernambuco.

SILVA, C. H. R. T. Recursos hídricos e Desenvolvimento Sustentável no Brasil. Boletim do Legislativo Brasília, 2012.

SILVA, D. M. DA; FACHIN, Z. Cobrança Pelo Uso Dos Recursos Hídricos: Instrumento De Gestão Face À Vulnerabilidade Da Água Potável. Revista Direitos Sociais e Políticas Públicas (UNIFAFIBE), v. 2, n. 2, p. 156-181, 2015.

SOARES, R. A. D. A. Proteção Ambiental e desenvolvimento econômico. Curitiba: Juruá, 2004.

SUPERINTERESSANTE. Detergente forma espuma nas águas dos rios. Disponível em:< http://super.abril.com.br/ideias/detergente-forma-espuma-nas-aguas-dos-rios/>. Acesso em: 30 mar. 2019. 